\title{
In normal subjects bracing impairs the function of the inspiratory muscles
}

\author{
E. Prandi*, J. Couture ${ }^{+}$, F. Bellemare* $*^{+}$
}

\begin{abstract}
In normal subjects bracing impairs the function of the inspiratory muscles. E. Prandi, J. Couture, F. Bellemare. (C)ERS Journal Ltd 1999.

ABSTRACT: Normal subjects can increase their capacity to sustain hyperpnoea by bracing their arms on fixed objects, a procedure which is also known to reduce dyspnoea in patients with chronic obstructive pulmonary disease (COPD). In the present study, it was tested whether bracing per se could improve the function of the diaphragm.

The effect of bracing on diaphragm function was studied in six normal subjects by recording changes in oesophageal $\left(\Delta P_{0}\right.$ es) and transdiaphragmatic $\left(\Delta P_{\mathrm{di}}\right)$ pressure during inspiratory capacity (IC) manoeuvres in the seated and upright postures, and in the seated posture, also during bilateral phrenic nerve stimulation (BPNS) at functional residual capacity (FRC). The pattern of ribcage motion and deformation associated with bracing and with diaphragm contraction was also evaluated using inductance plethysmography and magnetometers.

Bracing increased FRC by $>300 \mathrm{~mL}$ and reduced $\mathrm{IC}$ by $\sim 200 \mathrm{~mL}$, in both postures. $\triangle P$ di during BPNS decreased on average by $15 \%$ indicating an impaired diaphragmatic function. The ribcage was deformed with bracing and was more distortable during BPNS.

In conclusion, in normal subjects, bracing impairs the function of the inspiratory muscles and reduces ribcage stability. These negative effects cannot explain the improved capacity to sustain hyperpnoea when the arms are braced.

Eur Respir J 1999; 13: 1078-1085.
\end{abstract}

* Centre de recherche and ${ }^{+}$Dépt d'Anesthésie, Centre Hospitalier de 1'Université de Montréal, Université de Montréal, Montréal, Québec, Canada.

Correspondence: F. Bellemare

Centre de recherche du CHUM

Campus Hôtel-Dieu

3850 rue St-Urbain

Montréal

Québec H2W 1T8

Canada

Fax: 15148432715

Keywords: Chest wall mechanics

diaphragm

phrenic nerve stimulation

respiratory muscle

Received: August 121998

Accepted after revision January 281999

This study was supported by grants from the Association Pulmonaire du Québec, and the Conseil de Recherches Médicales du Canada.

Normal subjects can improve their capacity to sustain hyperpnoea by bracing their arms on fixed objects [1], but the mechanism is still unknown. It is common knowledge that patients with chronic obstructive pulmonary disease (COPD) can obtain relief of their dyspnoea by bracing their arms on fixed objects [2-4]. This effect of bracing on respiratory sensation in COPD patients has been attributed to an improved diaphragmatic length and function when leaning forward on fixed objects [3, 4]. It is not known whether bracing per se can also improve the function of the diaphragm and explain the improved capacity to sustain hyperpnoea under these conditions. The present study was designed to test this possibility by recording the effects of bracing on lung volume $(V \mathrm{~L})$, chest wall configuration and inspiratory capacity (IC) as well as on the capacity of the diaphragm to generate inspiratory pressures using bilateral phrenic nerve stimulation (BPNS).

\section{Materials and methods}

\section{Study subjects}

Six normal and lean subjects (four males and two females), between 22 and 46 yrs of age, were studied. Only one was experienced in respiratory mechanic studies and four were naive as to the hypothesis being tested and underlying physiology. All appeared healthy and were without signs of respiratory or muscular diseases. The protocol was approved by the local human ethics committee and all subjects gave their written informed consent.

\section{Study design}

The experimental protocol involved two sessions each on a separate day. In the first session the effect of bracing on $V \mathrm{~L}$, chest wall configuration and pressure at functional residual capacity (FRC) were measured as well as during tidal breathing (TB) and IC manoeuvres. The second session served to evaluate the effect of bracing on diaphragmatic function and ribcage stability using BPNS.

\section{Methods in session 1}

Subjects were studied both seated and upright. The sitting posture was the same as that described by BANZETT et al. [1]: subjects were seated on the front half of a chair and leaned forward with elbows braced on the table (braced) in half of the tests and elbows held just above the table (unbraced) in the other half, holding in their hands the mouthpiece/pneumotachograph assembly. In the erect 
posture, subjects braced and unbraced their hands on the table with arms stretched. In this posture, the mouthpiece/ pneumotachograph assembly was supported externally. In both postures, the distance from the subject to the table, the feet position and height of the chair were fixed. The braced-unbraced sequence was randomized.

Airflow was measured with a pneumotachograph connected to a mouthpiece and a differential pressure transducer (Validyne MP-45: $\pm 2 \mathrm{cmH}_{2} \mathrm{O}$; Validyne, Northridge, $\mathrm{CA}, \mathrm{USA}) . V \mathrm{~L}$ and lung volume changes $(\Delta V \mathrm{~L})$ were obtained by integration of the flow signal (Validyne FV 156 integrator). Two latex balloons (10 cm long), each mounted on polyethylene tubing (1.4 mm ID) and connected to pressure transducers were placed one in the mid-oesophagus to record the oesophageal pressure $\left(P_{\text {oes }}\right)$ and the other into the stomach to record the gastric pressure $(P \mathrm{ga})$. The difference between $P_{\text {oes }}$ and $P$ ga provided the transdiaphragmatic pressure $(P \mathrm{di})$.

Changes in the ribcage $\left(V_{\mathrm{rc}}\right)$ and abdomen $(V \mathrm{ab})$ volume were measured using respiratory inductance plethysmography (RIP; Respitrace, Respitrace Corp., Ardsley, NY, USA) with the bands placed at subaxillary and umbilical levels, respectively, and calibrated using the isovolume manoeuvre $[5,6]$. Changes in ribcage anteroposterior $(d \mathrm{rc}, \mathrm{AP})$ and lateral $(d \mathrm{rc}, \mathrm{LAT})$ diameters at the level of the 4 th intercostal space anteriorly were measured with pairs of linearized magnetometers calibrated against a ruler. In order to minimize skin motion artefacts, care was taken to position the magnetometer coils in an area free from excessive fat or muscle tissue. They were covered with large adhesive pads that prevented twisting and misalignment of the coils. All signals were analogue-to-digital converted, sampled at $200 \mathrm{~Hz}$ and stored on a personal computer for subsequent analysis using commercially available software (Acknowledge; BIOPAC Systems Inc., Santa Barbara, CA, USA).

Subjects were asked to breathe quietly, elevating or bracing their arms in each condition, and after the signals reached a steady state, changes of all the parameters studied were measured at FRC, as well as during TB and IC manoeuvres. At least 25 measurements at FRC and during $\mathrm{TB}$ and five measurements during IC manoeuvres were performed in each subject and condition.

\section{Methods in session 2}

On the second day, BPNS was employed to study the electromechanical coupling of the diaphragm [7] and the resistance of the ribcage to deformations $[8,9]$. All tests were performed in the sitting posture and in all tests $P_{0}$, $P$ ga, $P$ di $, V_{\mathrm{rc}}, V \mathrm{ab}, d \mathrm{rc}, \mathrm{AP}$ and $d \mathrm{rc}$,LAT were recorded as described before. The techniques employed to maximally and electrically stimulate the phrenic nerves bilaterally with single shocks and to record the compound motor action potentials (CMAPs) of the left and right costal diaphragms with surface electrodes and of the crural diaphragm with oesophageal electrodes have all been described previously [7]. Typically, five successive diaphragmatic twitches were recorded during brief periods $(\sim 10 \mathrm{~s})$ of airway occlusion with arms either braced or unbraced in an alternating sequence, each separated by periods of normal breathing. In five subjects, a second series of recordings was obtained in which $\Delta V \mathrm{~L}$ with bracing were prevented by always closing the airway in the unbraced condition. Between 20 and 40 twitches were recorded in each of the four conditions examined in each subject (i.e. between 80 and 120 twitches in each subject).

\section{Analysis of data}

The baseline values of all pressure and volume signals at end expiration, as judged from the volume tracing, recorded during TB and IC manoeuvres served to establish baseline values and to document FRC changes. Changes from these baseline values to end inspiration of all the variables served to document changes between positions during TB and IC manoeuvres. Changes in chest wall dimensions and pressures during maximal BPNS were measured from baseline values to the peak of the twitch contraction. The biphasic CMAPs from the three recording sites, after appropriate amplification and filtering (20-500 $\mathrm{Hz}$ ), were measured peak-to-peak. For graphical representations, all variables were measured relative to the corresponding baseline value at end expiration in this posture with the arms unbraced. For all the tests performed in this study, the data pertaining to a given subject and condition were averaged and used for statistical analysis. A one way analysis of variance (ANOVA) was employed for comparisons between the sitting and upright postures, while a paired Student's t-test was employed when the comparison was restricted to the braced and unbraced conditions in a given posture (SPSS Advanced statistics v.6.1; SPSS Inc., Chicago, IL, USA). Data are presented as group means \pm SD, unless otherwise indicated. The coefficient of variation $(\mathrm{CV})$ was used as a measure of repeatability.

\section{Results}

\section{Effects of bracing on functional residual capacity}

Selected tracings during TB when bracing and unbracing the arms in the seated posture are shown in figure 1. Changes of all mechanical variables at FRC for the group are presented in table 1 . Bracing produced a sustained increase in FRC of $>300 \mathrm{~mL}$ in both postures. In both postures, $P_{\text {oes, }} P_{\text {ga }}$ and $P$ di at end expiration all became significantly more negative with bracing (table 1 ).

\section{Effects of bracing during bilateral phrenic nerve stimula- tion}

Diaphragmatic responses. The CMAPs from the costal and crural diaphragmatic fibres did not significantly differ between the braced and unbraced conditions indicating a constant phrenic nerve stimulus (table 2). However, twitch $\Delta P_{\text {oes }}$ and twitch $\Delta P$ di both decreased significantly with bracing indicating an impaired diaphragmatic function. For the five subjects in whom this was tested, twitch $\Delta P$ oes and twitch $\Delta P$ di also decreased significantly with bracing when FRC changes were prevented.

Ribcage distortability. As shown in table 2, isolated diaphragmatic contractions reduced $V_{\mathrm{rc}}$ and $d_{\mathrm{rc}, \mathrm{AP}}$ but increased $d$ rc,LAT (figs. 2 and 3). These deformations 

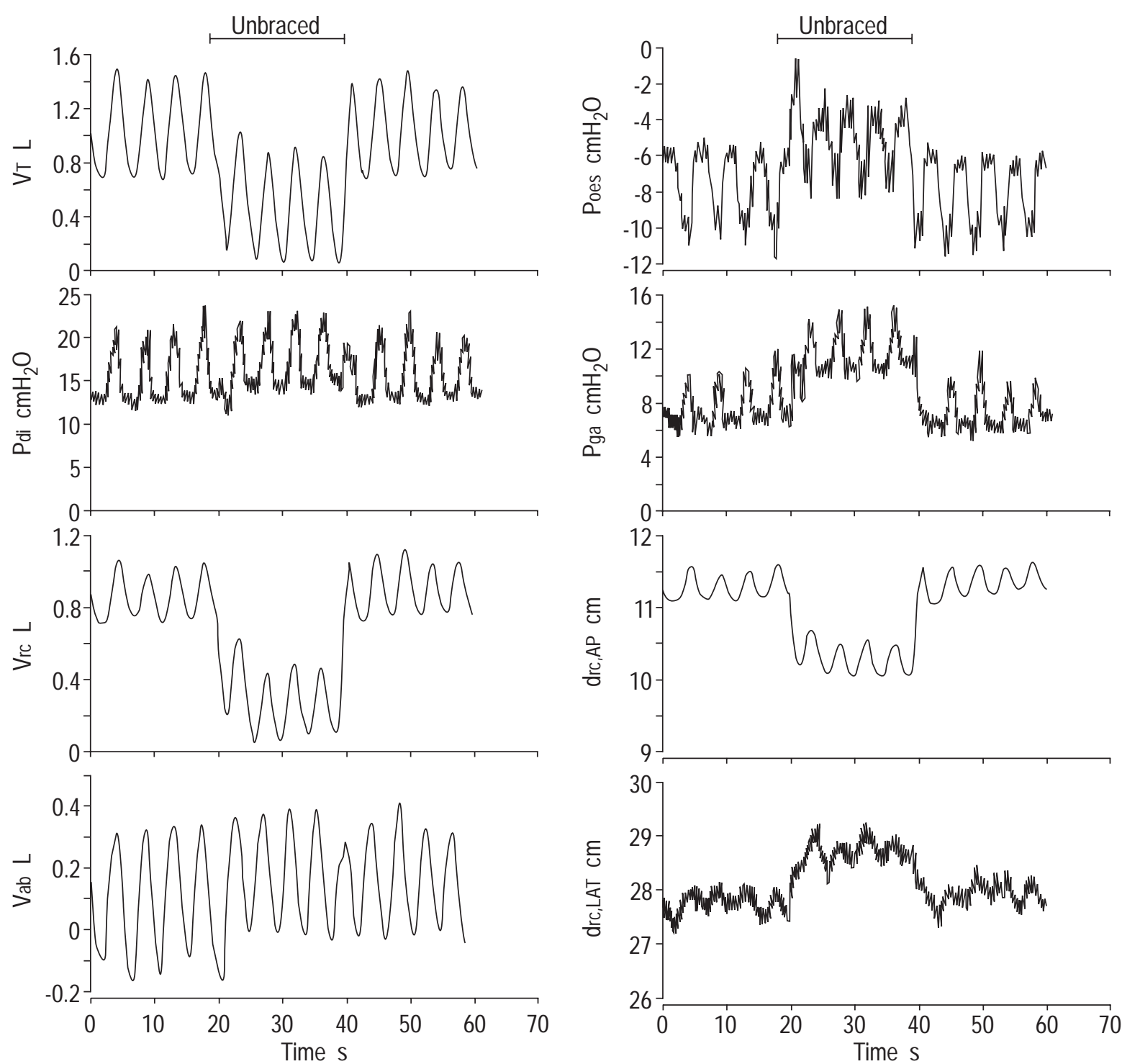

Fig. 1. - Records of tidal volume $(V \mathrm{~T})$, transdiaphragmatic pressure $(P \mathrm{di})$, oesophageal pressure $\left(P_{\mathrm{oes}}\right)$ and gastric pressure $(P$ ga $)$ during a bracedunbraced-braced sequence in a seated subject, and records of chest wall surface displacements corresponding to the same sequence. $V$ rc: ribcage or thoracic volume displacements; Vab: abdominal volume displacements; $d \mathrm{rc}$,AP: ribcage anteroposterior diameter; drc,LAT: ribcage lateral diameter.

were statistically significant and were exaggerated when the arms were braced, both when FRC increased and when it did not. Indeed, $d \mathrm{rc}, \mathrm{AP}$, was significantly greater with arms braced in spite of a smaller twitch $\Delta P$ di and twitch $\Delta P_{\text {oes. }} \Delta V_{\text {rc }}$ also tended to be greater with arms braced, although not significantly so. When normalized with respect to twitch $\Delta P_{\text {oes}}$, however, $\Delta V_{\mathrm{rc}} / \Delta P_{\text {oes }}$ increased significantly by $35.7 \pm 24.9 \%(\mathrm{p}<0.05)$ with bra- cing, a difference that was entirely accounted for by corresponding changes in $d \mathrm{rc}, \mathrm{AP}$.

\section{Effects of bracing on volume-pressure relationships}

The effects of bracing on the relationships between $V_{\mathrm{L}}$ and $P$ oes or $P$ ga changes are illustrated in figure 4 . The changes in $V \mathrm{~L}$ and $P$ oes with bracing appeared to occur

Table 1. - Variations of the mechanical variables at end-expiratory lung volume when bracing the arms in the sitting and upright postures

\begin{tabular}{lcccccccc}
\hline & $\begin{array}{c}\Delta V \mathrm{~L} \\
\mathrm{~L}\end{array}$ & $\begin{array}{c}\Delta P_{\mathrm{oes}} \\
\mathrm{cmH}_{2} \mathrm{O}\end{array}$ & $\begin{array}{c}\Delta P_{\mathrm{ga}} \\
\mathrm{cmH}_{2} \mathrm{O}\end{array}$ & $\begin{array}{c}\Delta P_{\mathrm{di}} \\
\mathrm{cmH}_{2} \mathrm{O}\end{array}$ & $\begin{array}{c}\Delta V_{\mathrm{rc}} \\
\mathrm{L}\end{array}$ & $\begin{array}{c}\Delta V \mathrm{ab} \\
\mathrm{L}\end{array}$ & $\begin{array}{c}\Delta d \mathrm{rc}, \mathrm{AP} \\
\mathrm{cm}\end{array}$ & $\begin{array}{c}\Delta d \mathrm{rc}, \mathrm{LAT} \\
\mathrm{cm}\end{array}$ \\
\hline Sitting & $0.34 \pm 0.16^{* * *}$ & $-1.73 \pm 1.00^{* * *}$ & $-2.11 \pm 1.27^{* * *}$ & $-0.36 \pm 0.61^{* *}$ & $0.21 \pm 0.26^{* * *}$ & $-0.01 \pm 0.08$ & $0.44 \pm 0.35^{* * *}$ & $-0.23 \pm 0.33^{* *}$ \\
Upright & $0.31 \pm 0.16^{* * *}$ & $-1.45 \pm 0.35^{* * *}$ & $-1.63 \pm 0.69^{* * *}$ & $-0.21 \pm 0.41^{+}$ & $-0.05 \pm 0.31$ & $0.04 \pm 0.10$ & $-0.07 \pm 0.39$ & $-0.11 \pm 0.46$ \\
\hline
\end{tabular}

Values are mean \pm SD variations from unbraced condition in six subjects of all mechanical variables. $V \mathrm{~L}$ : lung volume; Poes: oesophageal pressure; $P$ ga: gastric pressure; $P$ di: transdiaphragmatic pressure; $V$ rc: ribcage volume displacements; $V_{\text {ab: }}$ abdominal volume displacements; $d \mathrm{rc}, \mathrm{AP}$ : ribcage anteroposterior diameter; $d \mathrm{rc}, \mathrm{LAT}$ : ribcage lateral diameter. ${ }^{* *}: \mathrm{p}<0.01 ;{ }^{* * *}: \mathrm{p}<0.001 ;{ }^{+}: \mathrm{p}=0.05$, paired $\mathrm{t}$-test comparison between braced and unbraced conditions in either posture. 
Table 2. - Variations of the electrical and mechanical responses to phrenic nerve stimulation when the arms are braced and unbraced

\begin{tabular}{|c|c|c|c|c|c|c|c|c|c|}
\hline $\begin{array}{c}\Delta P_{\text {oes }} \\
\mathrm{cmH}_{2} \mathrm{O}\end{array}$ & $\underset{\mathrm{cmH}_{2} \mathrm{O}}{\Delta P_{\mathrm{ga}}}$ & $\begin{array}{c}\Delta P \mathrm{di} \\
\mathrm{cmH}_{2} \mathrm{O}\end{array}$ & $\begin{array}{c}\Delta V_{\mathrm{rc}} \\
\mathrm{L}\end{array}$ & $\underset{\mathrm{L}}{\Delta V_{\mathrm{ab}}}$ & $\begin{array}{c}d \mathrm{rc}, \mathrm{AP} \\
\mathrm{cm}\end{array}$ & $\begin{array}{l}d \mathrm{rc}, \mathrm{LAT} \\
\mathrm{cm}\end{array}$ & $\begin{array}{c}\text { CMAPoes } \\
\text { AU }\end{array}$ & $\begin{array}{c}\text { CMAPL } \\
\text { AU }\end{array}$ & $\begin{array}{c}\text { CMAPR } \\
\text { AU }\end{array}$ \\
\hline
\end{tabular}

Responses at variable FRC (n=6)

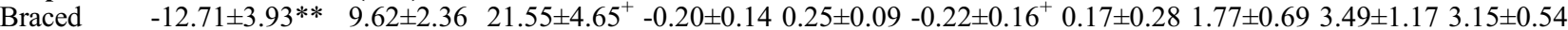

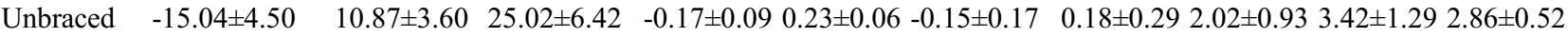

Responses at constant FRC $(\mathbf{n}=\mathbf{5})$

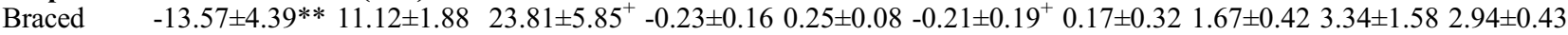

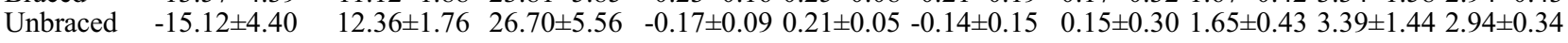

Values are mean changes $(\Delta)$ during the twitch contraction of the diaphragm in six subjects when functional residual capacity (FRC) was allowed to change between the braced and unbraced conditions (variable FRC) and when it was not (constant FRC). CMAPoes: compound motor action potential recorded with the oesophageal electrode; CMAPL, CMAPR: compound motor action potential recorded over the left and right costal surface of the diaphragm, respectively. For other definitions see footnote to table $1 .{ }^{* *}: \mathrm{p}<0.01 ;^{+}:$ $\mathrm{p}<0.02$, statistical comparisons between braced and unbraced conditions based on paired Student's t-test.

along a unique exponential function representing the volume-pressure relationship of the lungs, and which was not altered by bracing or by posture changes. The increased FRC with bracing caused TB to occur at a higher mean $V$ L but tidal volume $(V \mathrm{~T})$ was not different. $\Delta P$ ga during TB decreased significantly (ANOVA) with bracing from $8.02 \pm 2.95$ to $4.86 \pm 1.38 \mathrm{cmH}_{2} \mathrm{O}(\mathrm{p}<0.05)$ when seated and from $2.76 \pm 1.45$ to $2.61 \pm 1.33(\mathrm{p}<0.05)$ when upright. $\Delta P$ di during TB also tended to be smaller, but not significantly with arms braced (i.e. the horizontal difference in fig. 4 between $P$ oes and $P$ ga), particularly in the sitting posture.

As shown in figure 4, maximum lung inflation tended to increase in both postures with bracing. However, the changes in $P_{\text {oes }}$ and in maximum $V \mathrm{~L}$ caused by bracing were not significant and were not sufficient to balance the effect of bracing on FRC. Accordingly, $\Delta V \mathrm{~L}$ during IC manoeuvres decreased significantly by $\sim 200 \mathrm{~mL}$ in both postures with bracing (table 3 ), thus showing a reduction in the capacity of the inspiratory muscles to produce volume displacements. As shown in figure 2, Pga also became more negative with bracing in all conditions tested, causing a nearly parallel shift of the $V_{\mathrm{L}}$ versus $P$ ga relationship to the left. This shift was greater when seated than when upright.

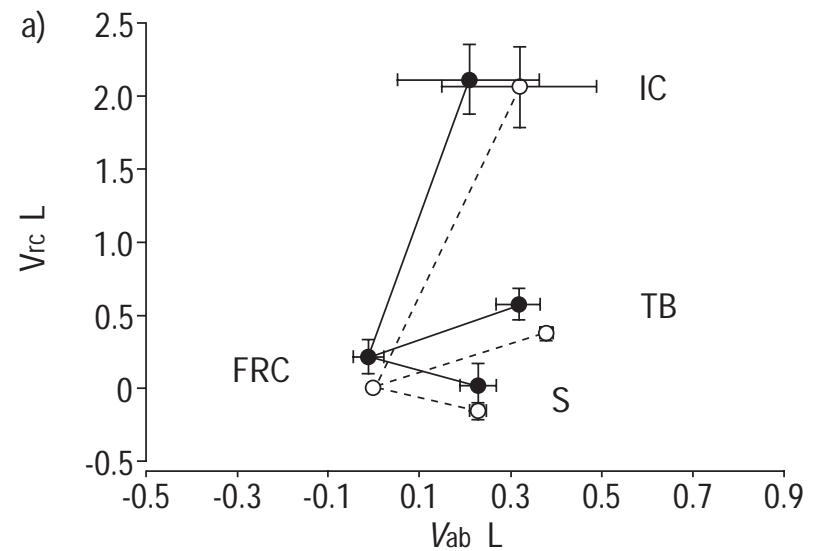

\section{Effects of bracing on chest wall configuration}

Konno-Mead plots of $V_{\mathrm{rc}}$ versus $V_{\mathrm{ab}}$ under the different experimental conditions examined are illustrated in figure 2 [5]. In the sitting posture, the $V_{\mathrm{rc}}$ versus Vab relationship was shifted upward with bracing. As shown in table 1, this sustained increase of $V_{\mathrm{rc}}$ in this posture was statistically significant whereas $V$ ab did not change significantly. By contrast, in the upright posture, no significant change was noted in the $V_{\mathrm{rc}}$ versus $V_{\mathrm{ab}}$ relationship in spite of comparable changes of FRC (table 1). As shown in figure 2, there was a tendency for $V$ ab to increase at FRC and during IC manoeuvres in this posture, but these changes were small and not significant. $\Delta V_{\mathrm{rc}}$ and $\Delta V_{\mathrm{ab}}$ during TB and IC manoeuvres were not significantly different with bracing. As shown in table 1, FRC changes caused by bracing were not accurately reflected in surface displacements as measured by RIP (i.e. the sum of $\Delta V_{\mathrm{rc}}$ and $\Delta V \mathrm{ab}$ ). In the sitting posture, only about two-thirds of $\triangle \mathrm{FRC}$ could be accounted for by measured chest wall displacements (table 1). In the upright posture, none of the $\triangle F R C$ could be accounted for by these displacements.

\section{Effects of bracing on ribcage shape}

In the seated posture $d \mathrm{rc}, \mathrm{AP}$ increased significantly with bracing (table 1). By contrast, drc,LAT decreased

b)

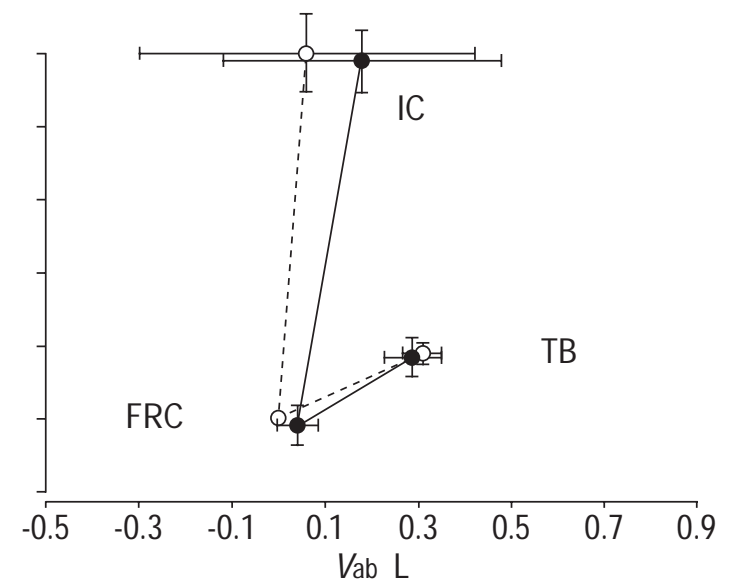

Fig. 2. - Relationships for the group between ribcage volume $(V \mathrm{rc})$ and abdominal volume $(V \mathrm{ab})$ as measured with the respiratory inductance plethysmograph at functional residual capacity (FRC), at the end of a normal tidal breath (TB) and an inspiratory capacity manoeuvre (IC) as well as at the peak of stimulated (S) twitch contraction of the diaphragm when the arms are braced $(\bullet)$ or unbraced $(\bigcirc)$ in the seated (a) and upright (b) postures. Values are mean \pm SEM in six subjects, and are measured relative to FRC values in the posture with arms unbraced. 

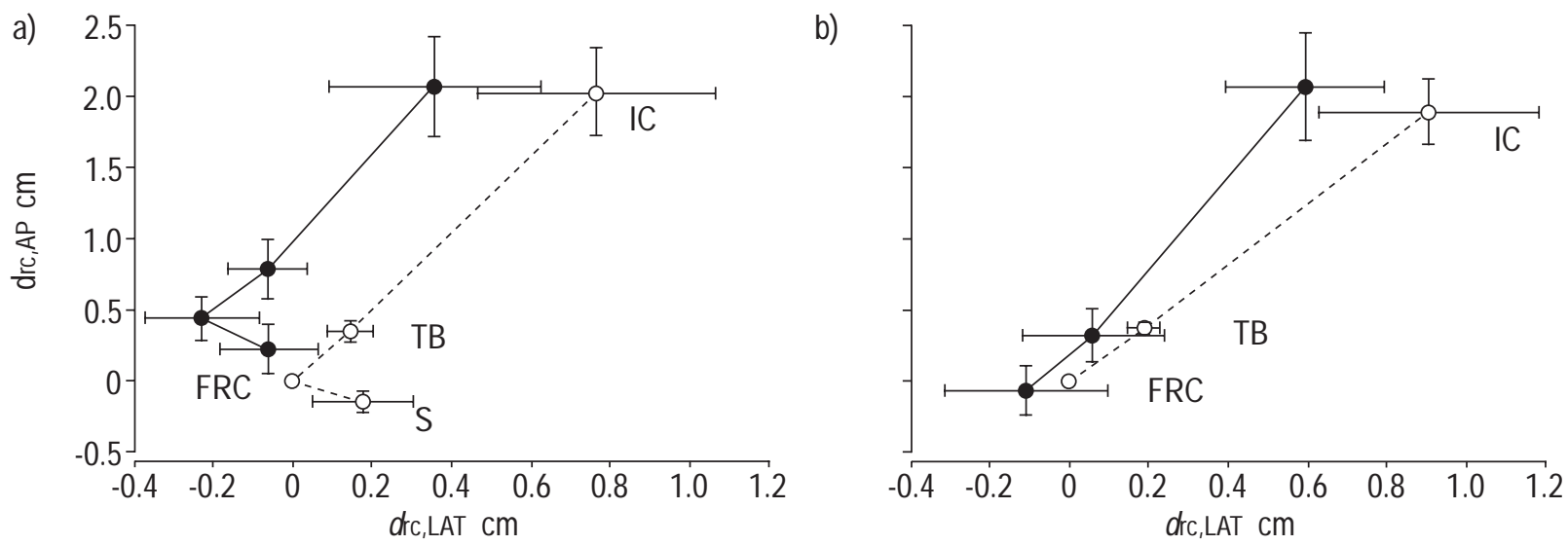

Fig. 3. - Relationships for the group between ribcage anteroposterior $(d \mathrm{rc}, \mathrm{AP})$ and lateral $(d \mathrm{rc}, \mathrm{LAT})$ diameters as measured with magnetometers at the level of 4th intercostal space anteriorly at functional residual capacity (FRC), at the end of a normal tidal breath (TB) and an inspiratory capacity manoeuvre (IC), as well as at the peak of a stimulated (S) twitch contraction of the diaphragm when the arms are braced $(\bullet)$ or unbraced (O) in the seated (a) or upright (b) postures. Values are mean \pm SEM in six subjects, and are measured relative to FRC values in posture with arms unbraced.

significantly, thus indicating a distortion of the ribcage with bracing. As shown in figure 3, the drc,AP versus $d \mathrm{rc}, \mathrm{LAT}$ relationship was shifted to the left with bracing. Hence the ribcage distortions persisted during TB and IC manoeuvres. A similar tendency was also observed in the upright posture, but the changes were less marked and not statistically significant. As shown in figure 3, the distortions of the ribcage caused by bracing were partially reversed during BPNS in the seated posture.

\section{Coefficients of variation}

The CV for repeated measures of $\Delta V \mathrm{~L}$ during IC manoeuvres for the group was systematically greater when the arms were braced $(6.63 \pm 1.37 \%)$ than when they were unbraced $(3.98 \pm 1.51 \%)$. For all conditions tested, CV of twitch $\triangle P$ di during BPNS was $10.45 \pm 2.42 \%$.

\section{Discussion}

The present study has shown that, in normal subjects, bracing the arms on fixed objects reduces the capacity of the inspiratory muscles to produce volume displacements

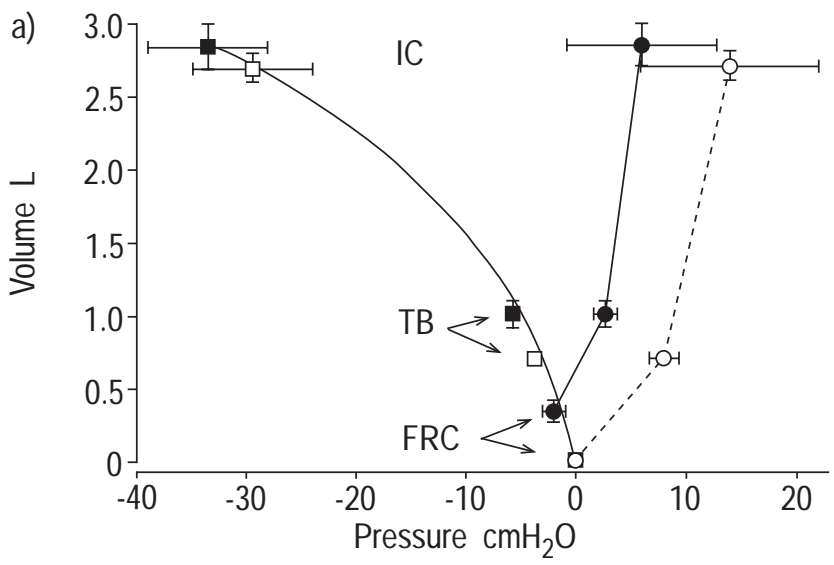

during IC manoeuvres both seated and upright. In the seated posture, the capacity of the diaphragm to lower pleural pressure and to increase $P$ di during isolated twitch contractions was also reduced with bracing. Collectively, these results suggest that bracing did not only improve the function of the inspiratory muscles but also impaired it.

The reduced capacity of the inspiratory muscles to produce volume displacements was clearly explained by the sustained increase of FRC caused by bracing but also by the incapacity of the inspiratory muscles to further expand the lungs at total lung capacity (TLC). The curvilinear nature of the volume-pressure curve of the lungs by allowing greater volume changes at FRC than at TLC for a given pressure change also contributed to this limitation.

The increased FRC with bracing, by allowing the diaphragm to shorten, can also explain the observed reduction of the capacity of this muscle to produce inspiratory pressure during BPNS. The $15 \%$ reductions of twitch $\triangle P$ oes and twitch $\Delta P$ di with bracing were indeed of the same magnitude as could be predicted from earlier studies for comparable changes in $V_{\mathrm{L}}[10,11]$. In the absence of abdominal expansion, diaphragm shortening with bracing should be related to ribcage expansion and to an axial and

b)

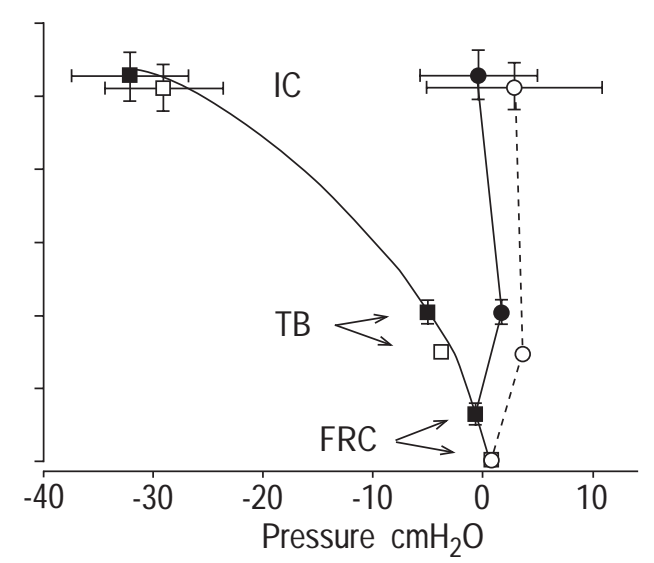

Fig. 4. - Relationships for the group between lung volume and oesophageal ( $P_{\text {oes; }}$ squares) and gastric $(P$ ga; circles) pressures at functional residual capacity (FRC) as well as at the end of a tidal breath (TB) and an inspiratory capacity manoeuvre (IC) when the arms are braced (closed symbols) or unbraced (open symbols) in the seated (a) and upright (b) postures. Values are mean \pm SEM in six subjects, and are measured relative to FRC values in the posture with arms unbraced. The volume versus Poes relationship in both postures were fitted with an exponential function of the form $y=a+b e^{-k x}$. 
Table 3. - Variations of the mechanical variables during inspiratory capacity manoeuvres when the arms are braced or unbraced in the sitting and in the upright postures

\begin{tabular}{lcccccccc}
\hline & $\begin{array}{c}\Delta V \mathrm{~L} \\
\mathrm{~L}\end{array}$ & $\begin{array}{c}\Delta P_{\mathrm{oes}} \\
\mathrm{cmH}_{2} \mathrm{O}\end{array}$ & $\begin{array}{c}\Delta P \mathrm{ga} \\
\mathrm{cmH}_{2} \mathrm{O}\end{array}$ & $\begin{array}{c}\Delta P_{\mathrm{di}} \\
\mathrm{cmH}_{2} \mathrm{O}\end{array}$ & $\begin{array}{c}\Delta V_{\mathrm{rc}} \\
\mathrm{L}\end{array}$ & $\begin{array}{c}\Delta V_{\mathrm{ab}} \\
\mathrm{L}\end{array}$ & $\begin{array}{c}\Delta d \mathrm{rc}, \mathrm{AP} \\
\mathrm{cm}\end{array}$ & $\begin{array}{c}\Delta d \mathrm{rc}, \mathrm{LAT} \\
\mathrm{cm}\end{array}$ \\
\hline Sitting braced & $2.50 \pm 0.22^{+*}$ & $-31.34 \pm 11.48$ & $8.40 \pm 15.86^{* * *}$ & $39.65 \pm 22.95^{* *}$ & $1.89 \pm 0.51^{*}$ & $0.24 \pm 0.35$ & $1.63 \pm 0.62$ & $0.72 \pm 0.76$ \\
Sitting unbraced & $2.69 \pm 0.22^{*}$ & $-29.41 \pm 12.24$ & $14.25 \pm 18.12^{* * *}$ & $43.66 \pm 25.34^{* *}$ & $2.05 \pm 0.62^{*}$ & $0.33 \pm 0.38$ & $2.03 \pm 0.68$ & $0.78 \pm 0.68$ \\
Upright braced & $2.31 \pm 0.42^{+}$ & $-30.67 \pm 11.81$ & $0.74 \pm 11.34$ & $31.41 \pm 20.84$ & $2.45 \pm 0.59$ & $0.16 \pm 0.61$ & $2.13 \pm 0.53$ & $0.71 \pm 0.69$ \\
Upright unbraced & $2.54 \pm 0.37$ & $-28.73 \pm 11.87$ & $2.31 \pm 17.34$ & $30.69 \pm 25.94$ & $2.46 \pm 0.59$ & $0.07 \pm 0.81$ & $1.88 \pm 0.52$ & $0.91 \pm 0.62$ \\
\hline
\end{tabular}

All values are mean \pm SD change from end-expiratory level to maximum lung inflation in six subjects. For definitions see footnote to table 1. Comparison between braced and unbraced conditions and between posture based on ANOVA. *: $\mathrm{p}<0.05 ; * *: \mathrm{p}<0.01 ; * * *$ : $\mathrm{p}<0.001$, sitting versus upright; ${ }^{+}: \mathrm{p}<0.01$, braced versus unbraced.

cephalad motion of the costal insertions of the diaphragm relative to its dome $[12,13]$. As inferred by LoRING and MeAD [12] and MEAD et al. [13], diaphragm shortening should be nearly as large in a breath involving ribcage expansion alone than in a breath taken along the relaxation configuration and which involves both ribcage and abdominal expansion. Although changes in $V \mathrm{~L}$ and diaphragm length are sufficient to explain the observed reductions in twitch pressures when the arms are braced, they did not appear to be necessary. Comparable changes in twitch $\Delta P$ oes and twitch $\Delta P$ di were observed with bracing even when lung volume changes were prevented (table 2). Thus other factors are likely to be involved.

From the present data, two other possible factors can be suggested. In the seated posture, the ribcage was deformed and became more circular with bracing as shown by a greater $d \mathrm{rc}, \mathrm{AP}$ and a smaller $d \mathrm{rc}, \mathrm{LAT}$ (table 1 and fig. 3 ). The impact of this kind of distortion on diaphragm geometry and function is not known at present. However, these distortions could modify the two principal radii of curvature of the diaphragm in the coronal and sagital planes and in this way modify the electromechanical coupling of the diaphragm and reduce its pressure-generating capacity [14].

The ribcage also appeared more distortable when the arms were braced independently of FRC changes as shown by the greater twitch $d \mathrm{rc}, \mathrm{AP} / \Delta P_{\text {oes }}$ and twitch $\Delta V_{\mathrm{rc}} / \Delta P_{\mathrm{oes}}$ ratios. A greater ribcage distortability during isolated diaphragmatic contractions could be caused by a smaller zone of apposition between the costal diaphragm and the lower ribcage [12-14] or by a reduced mechanical linkage between the upper lung-apposed ribcage and the lower diaphragm-apposed ribcage $[8,9]$. In both cases, a smaller fraction of the pressure exerted by the diaphragm on the lower ribcage would be transmitted to the upper ribcage with a consequent decrease in $\Delta P_{\text {oes. As this }}$ should also imply a greater shortening of the diaphragm during the twitch, twitch $\Delta P$ di should also have been reduced by this mechanism. Because the ribcage expanded in the seated posture with bracing, when $V \mathrm{~L}$ was allowed to change and when it was not, the zone of apposition of the diaphragm with the ribcage should have been reduced $[12,13]$. In addition, when FRC changes were prevented, the ratio $\Delta V \mathrm{ab} / \Delta P$ ga during the twitch increased significantly when the arms were braced suggesting a greater abdominal wall compliance, and hence a greater shortening of the diaphragm during the twitch. However, the contribution of these or other mechanisms to the observed reductions in twitch $\Delta P_{\text {oes }}$ and twitch $\Delta P$ di cannot be determined from the present measurements.

\section{Mechanism for increased functional residual capacity}

CRAIG [15] has shown, some time ago, that supporting the weight of the arms in the seated posture increases FRC by $\sim 160 \mathrm{~mL}$. This effect was further shown by the author to be exaggerated when the arms are supported in the leaning forward position, in which case FRC increased by $360 \mathrm{~mL}$. This value is very close to the value observed here in the same posture (i.e. $340 \mathrm{~mL}$ ). The present results thus confirm the findings of CRAIG [15], and even extend these findings to the upright posture.

CRAIG [15] attributed the increased FRC when the arms were supported in the seated posture to removal of the expiratory effect exerted on the chest wall by the weight of the pectoral girdle which was estimated to be between $7-9 \mathrm{~kg}$. The further increase in FRC when leaning forward was attributed to gravitational forces acting on the abdomen and stretching the anterior abdominal wall. In the present study, however, the abdomen did not expand with bracing, at least not at the level of the umbilicus. This mechanism, therefore, cannot account for the observed changes in FRC.

The pattern of chest wall motion and the associated changes in $P$ oes, $P$ ga and $P$ di that were observed with bracing in this study are consistent with the recruitment of inspiratory ribcage muscles. Indeed, the ribcage expanded in the seated posture causing the observed reductions in $P$ oes and $P$ ga while the diaphragm remained relaxed. Furthermore, because the abdomen did not expand radially with bracing, the fall in Pga and increased FRC could not be attributed to relaxation of the abdominal muscles.

Several ribcage mechanisms could have contributed to reduce $P$ ga when the arms were braced. Firstly, the fall in pleural pressure caused by ribcage muscle contraction could have been transmitted across the diaphragm via the lungs. Secondly, radial expansion of the lower ribcage in the zone of apposition and of the immediately adjacent abdominal wall would tend to expand the abdominal compartment and in this way would tend to lower abdominal pressure. Cephalad motion of the ribcage would also tend to expand the abdominal compartment axially, and in this way would also tend to lower abdominal pressure.

Although the above-mentioned ribcage mechanisms should be responsible for the fall in $P$ ga with bracing, they do not exclude the possibility of a lesser abdominal muscle activity with bracing. In fact, if the abdominal muscles were active in the unbraced condition, then their activity 
would need to be reduced in order to maintain $V \mathrm{ab}$, constant when abdominal pressure was reduced by the action of the ribcage muscles. By doing so, the weight of the abdominal contents (or part of it) would be shifted from the anterior abdominal wall to the inspiratory ribcage muscles without necessarily changing the radial dimensions of the abdomen at the level of the umbilicus. Other mechanisms could explain the constancy of $V \mathrm{ab}$ in this study. Abdominal pressure changes could have been non-uniform and greater in the upper than in the lower part of the abdomen [16]. Alternatively, because the trunk was flexed in the seated posture, the abdominal compartment could have been operating on the flat part of its pressure-volume relationship and be relatively insensitive to abdominal pressure changes $[6,13,14]$.

The muscles most likely to be responsible for the observed ribcage expansion when the arms were braced in the seated posture, are the accessory muscles of the pectoral girdle which have an insertion on the ribs. The pectoralis minor and the inferior portion of the serratus anterior would be the best candidates. When the scapula is fixed, these muscles, by elevating the ribs, would indeed exert an inspiratory action on the ribcage causing pleural pressure to decrease [17]. The lowering of pleural and abdominal pressures in turn could be responsible for the observed reductions of $d \mathrm{rc}$,LAT with bracing. A similar pattern of ribcage distortions has been described in $\mathrm{C} 1$ tetraplegic patients who must rely exclusively on the recruitment of the strenocleidomastoid muscle for breathing [18]. The bilateral contraction of the serratus anterior, whose fibres run laterally round the ribcage, could also contribute to this distortion by compressing the ribcage laterally. The accessory muscles of the pectoral girdle could thus be responsible for the fall in $P$ oes and $P$ ga as well as for the ribcage distortions that were observed with bracing (figs. $2-4)$. The fact that these effects were nearly constant under the different experimental conditions examined suggests that the main action of these accessory muscles was essentially a tonic and weight bearing one and not a phasic one.

There was a tendency for $P_{\text {oes }}$ to be more negative at maximum lung inflation in both postures, which could suggest a somewhat greater lung expansion with bracing. This difference was not, however, significant. These results are consistent with those of BANZETT et al. [1] who could not demonstrate systematic changes in maximum inspiratory flow rates or in vital capacity with bracing in normal subjects. In their study, vital capacity increased by $200 \mathrm{~mL}$ in two subjects but did not change in the other two. Thus, the major net effects of bracing on the chest wall are a sustained elevation of end-expiratory lung volume and a consequent reduction of IC.

It is of particular interest that accessory inspiratory muscles having a net inspiratory action on the ribcage when the arms are braced, did not improve ribcage stability during superimposed diaphragmatic twitch contractions. This is particularly surprising in view of the fact that the action of these two muscle groups on the ribcage was clearly antagonistic and almost exactly opposite (fig. 3). Additional studies will be required to resolve this paradox.

Although the action of the accessory muscles of the pectoral girdle may not be expected to change with posture, the inspiratory action of these muscles was clearly less in the upright than in the seated posture. Firstly the ribcage did not expand radially and $d \mathrm{rc}$,AP did not increase with bracing in the upright posture. Secondly, the reduction of $d \mathrm{rc}$,LAT was substantially smaller in this posture. Finally, the fall in $P$ ga with bracing was also substantially smaller in this posture suggesting a less efficient inspiratory action of these accessory muscles.

Other mechanisms are therefore required to explain the increased FRC in the upright posture with bracing. In this posture, spinal extension or spinal elongation could have occurred, expanding the ribcage and abdomen axially. Spinal extension or flexion has been shown to constitute an important degree of freedom of motion of the chest wall [6]. Shifting weight from the spine to the arms with bracing could conceivably extend the spine. At constant $V \mathrm{~L}$, spinal extension is associated with radial compression of both the ribcage and abdomen [6]. Because $V_{\mathrm{rc}}$ and $V_{\mathrm{ab}}$ did not decrease with bracing in the upright posture, spinal extension would increase $V$ L. Shifting weight from the spine to the hands with bracing could also have elongated the spine by decompressing the intervertebral discs. Each intervertebral disc would need to expand $<1 \mathrm{~mm}$ to accommodate a $300 \mathrm{~mL}$ increase of FRC in this posture. The extent to which spinal extension or elongation contributed to $\triangle \mathrm{FRC}$ in the upright posture cannot be determined from the present measurements. However to the extent that this mechanism was involved, then these results would suggest that, in the upright posture, the contraction of the accessory muscles of the pectoral girdle was just sufficient to balance the fall in pleural pressure caused by spinal extension or elongation.

In summary, the present study has shown that, in normal subjects, bracing the arms on fixed objects impairs the capacity of the inspiratory muscles to produce volume displacements and also impairs the capacity of the diaphragm to generate inspiratory pressures at functional residual capacity. Furthermore, the ribcage was distorted with bracing and was more easily distorted during isolated diaphragmatic contractions. Clearly, none of these effects can explain the improved capacity to sustain hyperpnoea reported before when the arms are braced [1]. Bracing was, however, associated with smaller gastric and transdiaphragmatic pressure swings during tidal breathing, particularly in the seated posture, two factors which could potentially improve the endurance of the inspiratory muscles during maximum ventilatory tasks and in this way explain the improved capacity to sustain hyperpnoea with bracing.

\section{References}

1. Banzett BR, Topulos GP, Leith DE, Nations CS. Bracing the arms increases the capacity for sustained hyperpnea. Am Rev Respir Dis 1988; 138: 106-109.

2. Barach AL. Chronic obstructive lung disease: postural relief of dyspnea. Arch Physi Med Rehabil 1974; 55: 494504.

3. Sharp JT, Druz WS, Moisan T, Foster J, Macnach W. Postural relief of dyspnea in severe chronic obstructive pulmonary disease. Am Rev Respir Dis 1980; 122: 201211.

4. Druz WS, Sharp JT. Electrical and mechanical activity of the diaphragm accompanying body position in severe chronic obstructive pulmonary disease. Am Rev Respir Dis 1982; 125: 275-280. 
5. Konno K, Mead J. Measurement of separate volume changes of the rib cage and abdomen during breathing. $J$ Appl Physiol 1967; 22: 407-422.

6. Smith JC, Mead J. Three degree of freedom description of movement of the human chest wall. J Appl Physiol 1986; 60: 928-934.

7. Bellemare F, Bigland-Richtie B. Assessment of human diaphragm strength and activation using phrenic nerve stimulations. Respir Physiol 1984; 58: 263-277.

8. Chihara K, Kenyon CM, Macklem PT. Human rib cage distortability. J Appl Physiol 1996; 81: 437-447.

9. Ward ME, Ward JW, Macklem PT. Analysis of human chest wall motion using a two-compartment ribcage model. J Appl Physiol 1988; 65: 2181-2189.

10. Johnson BD, Babcock MA, Suman OE, Dempsey JA. Exercise-induced diaphragmatic fatigue in healthy humans. J Physiol (London) 1993; 460: 385-405.

11. Similowski T, Yan S, Gauthier AP, Macklem PT, Bellemare F. Contractile properties of the human diaphragm during chronic hyperinflation. $N$ Engl J Med 1991; 325: 917-923.

12. Loring SH, Mead J. Action of the diaphragm on the rib- cage inferred from a force balance equation. $J$ Appl Physiol 1982; 53: 756-760.

13. Mead J, Loring SH, Smith JC. Volume displacements of the chest wall and their mechanical significance. In: Roussos C, ed. The Thorax, Part A: Physiology. Lung Biology in Health and Disease. Vol. 85. New York, Dekker, 1995; pp. 565-586.

14. Smith JC, Loring SH. Passive mechanical properties of the chest wall. In: Macklem PT, Mead J, eds. Handbook of Physiology, Section 3. The Respiratory System. Vol. 3. Bethesda MD, American Physiological Society 1986; pp. 429-442.

15. Craig AB. Effects of position on expiratory reserve volume of the lungs. J Appl Physiol 1960; 15: 59-61.

16. Decramer M, DeTroyer A, Kelly S, Zocchi L, Macklem PT. Regional differences in abdominal pressure swings in dogs. J Appl Physiol 1984; 57: 1682-1687.

17. Williams PL, Warwick R, Dyson M, Bannister LH, eds. Gray's Anatomy. 37th Edn. New York, Churchill Livingstone, 1989; pp. 610-614.

18. De Troyer A, Estenne M, Vincken W. Ribcage motion and muscle use in high tetraplegics. Am Rev Respir Dis 1986; 133: 1115-1119. 